\title{
CLINICAL PROFILE AND TREATMENT OUTCOME OF LOWER MOTOR NEURON FACIAL NERVE PALSY IN A UNIVERSITY TEACHING HOSPITAL IN SOUTH INDIA
}

\author{
Lily Daniel1 ${ }^{1}$ Vaishnavi ${ }^{2}$, Varshini Varadaraj ${ }^{3}$, Preethi $K^{4}$
}

${ }_{1}^{1}$ Assistant Professor, Department of Ophthalmology, ACS Medical College, Chennai, Tamilnadu.

2Senior Resident, Department of Ophthalmology, Sri Ramachandra University, Chennai, Tamilnadu.

3Postdoctoral Research Fellow, Johns Hopkins Hospital, Baltimore, Maryland, USA.

${ }_{4}^{4}$ Postgraduate Student, Department of Ophthalmology, Sri Ramachandra University, Chennai, Tamilnadu.

\begin{abstract}
BACKGROUND

Lower motor neuron facial palsy is characterised by paralysis of facial muscles on the affected side. The aetiology of facial nerve palsy is myriad. The most common being Bell's palsy. Bell's palsy is of acute onset and considered to be idiopathic in origin, even though lots of causative factors including viral agents, autoimmunity and vascular origin have been suggested. Prompt management of facial nerve palsy is required to ensure corneal clarity and to reduce long-term visual and cosmetic disability.

Aims and Objectives- To study the aetiology, clinical profile of lower motor neuron (LMN) facial nerve palsy in a University Teaching Hospital and to determine the treatment outcome.
\end{abstract}

\section{MATERIALS AND METHODS}

This is a retrospective descriptive study of 99 eyes of 95 patients who had LMN facial nerve palsy over a period of 3 years. The Best Corrected Visual Acuity (BCVA), grading of lagophthalmos (House-Brackmann), assessment of lid laxity and Bell's phenomenon, slit lamp grading of punctate epitheliopathy, corneal sensation and fundus of 95 patients were studied and the type of management that they were subjected to were analysed and the treatment outcome determined.

\section{RESULTS}

The most common aetiology of LMN facial palsy was found to be Bell's (70.5\%), while other causes included post-traumatic, congenital or Ramsay Hunt syndrome. Bell's palsy of less than a week's duration responds well to systemic antivirals, steroids and tear substitutes. For facial palsy of more than six months' duration, Gold Weight Implant (GWI) is an effective procedure for providing adequate lid closure. Lateral Tarsal Strip (LTS) provides good apposition of the lower lid to globe. Lateral tarsorrhaphy (LT) is still the procedure of choice when there is impaired corneal sensation.

\section{CONCLUSION}

Bell's palsy is the most common aetiology of LMN facial palsy. This retrospective case study highlights the significance of early recognition of LMN facial palsy and its prompt treatment. Early medical treatment of Bell's palsy promotes complete recovery of facial nerve function. The sequelae of facial palsy can be adequately corrected surgically, providing good cosmetic and functional outcome.

\section{KEY WORDS}

Facial Nerve Paralysis, Lower Motor Neuron, Aetiology, Treatment Outcome.

HOW TO CITE THIS ARTICLE: Daniel L, Vaishnavi R, Varadaraj V, et al. Clinical profile and treatment outcome of lower motor neuron facial nerve palsy in a University Teaching Hospital in South India. J. Evolution Med. Dent. Sci. 2018;7(19):2410-2414, DOI: $10.14260 /$ jemds/2018/542

\section{BACKGROUND}

LMN facial palsy affects the ipsilateral side of face. Long standing facial palsy produces significant physical and psychosocial disability. The aetiology of facial nerve palsy is myriad, the most common being idiopathic, neoplastic and infectious. Prompt management is required to ensure corneal clarity and to reduce long-term visual and cosmetic disability. We report the clinical profile and treatment outcome of 99 eyes of 95 patients who attended the Ophthalmic Department of University Teaching Hospital with cross referrals from the

'Financial or Other Competing Interest': None.

Submission 27-03-2018, Peer Review 20-04-2018,

Acceptance 26-04-2018, Published 07-05-2018.

Corresponding Author:

Vaishnavi R,

Senior Resident, Department of Ophthalmology,

Sri Ramachandra University, Porur-600116,

Chennai, Tamilnadu.

E-mail: vaishnaviravi@gmail.com

DOI: $10.14260 /$ jemds $/ 2018 / 542$

\section{(c) (i) $(9)$}

departments of Internal Medicine, Otorhinolaryngology and Neurology. This is a hospital-based, single-centre, retrospective record based analysis.

The degree of functional impairment in facial palsy depends on the amount of paralysis and the patient's age. The younger the patient, the lesser is the degree of brow ptosis and ectropion because of stronger tissue support.[1] Younger patients afflicted with facial palsy usually present with lagophthalmos, while older patients present with lagophthalmos, brow ptosis and paralytic ectropion [Fig. 1]. Long standing facial nerve palsy causes exposure keratitis, conjunctivalisation of cornea and even loss of vision [Fig. 2]. LTS corrects the paralytic ectropion and also raises the lateral canthal height.[1,2] Medial Spindle Stitch (MSS) causes additional inversion of the punctum. [1] Lateral tarsorrhaphy is a swift, simple and easily reversible surgical procedure that can prevent or treat corneal exposure. ${ }^{[3]}$ A principle disadvantage of the procedure is that it is cosmetically not appealing, does not address the problems of watering and compromises peripheral vision. GWI in the upper eyelid is an 
effective procedure to improve eye closure and reduce corneal exposure. ${ }^{[3,4]}$ Brow lift eliminates the superior visual field defect aggravated by brow ptosis.[1]

A combination of procedures eliminates the need for large tarsorrhaphies and is likely to produce good functional outcome and better cosmetic appearance. However, tarsorrhaphies are indicated in the presence of impaired corneal sensation.

\section{Objective}

To study the aetiology, clinical profile of lower motor neuron (LMN) facial nerve palsy in a University Teaching Hospital and to determine the treatment outcome.

\section{MATERIALS AND METHODS}

This was a retrospective descriptive study. The aetiology of 95 patients who presented with peripheral facial palsy to the outpatient department of a multispeciality hospital over a period of 3 years were studied and their clinical profile and treatment outcome analysed. The minimum post-operative follow-up was for a period of six months. All patients underwent detailed ocular examination which included BCVA, grading of lagophthalmos (House-Brackmann),[9] assessment of lid laxity and Bell's phenomenon, slit lamp grading of punctate epitheliopathy, corneal sensation and fundus examination. Patients with upper motor neuron palsy were excluded from the study. All patients with Bell's palsy of less than a week's duration underwent medical therapy, which included a course of oral Acyclovir (Acivir, Cipla, India) $400 \mathrm{mg}$ qid for 7 days and oral prednisolone (Wysolone, Wyeth, India) $1 \mathrm{mg}$ per kg tapered over two weeks, ocular surface lubricants and physiotherapy. Those patients with Bell's palsy of more than a week's duration were treated with ocular surface lubricants containing Hydroxypropyl Methylcellulose $0.7 \%$ and physiotherapy. All patients with persistent facial nerve palsy of more than 6 months duration underwent surgery. Patients with only lagophthalmos (Group 1) underwent Gold weight implant (Appasamy Associates, Puducherry, India) in the upper eyelid after a gold weight trial (Fig. 4a, b). Patients with lagophthalmos and paralytic ectropion (Group 2) underwent LTS with or without MSS, because they were not keen on a GWI. Patients with lagophthalmos and paralytic ectropion who were willing for GWI (Group 3) underwent GWI apart from LTS and MSS (Fig. $5 \mathrm{a}, \mathrm{b})$. Patients with lagophthalmos, paralytic ectropion and brow ptosis (Group 4) underwent additional Transeyelid Browplasty. Patients with impaired corneal sensation (Group 5) underwent lateral tarsorrhaphy. None underwent mid facial lift.

The primary outcome measured in those who underwent medical therapy were reduction in lagophthalmos and resolution of punctate staining of the cornea. Secondary outcome measures was reduction in the frequency of application of tear substitutes. Primary outcome measures in those who underwent surgery were reduction in lagophthalmos (Grade 2), good eyelid, opposition to globe and reduction in punctuate staining of cornea. Secondary outcome measures were reduction in the frequency of tear substitutes, improvement of epiphora and good cosmesis in terms of patient satisfaction.

\section{RESULTS}

Of the 95 patients with lower motor neuron palsy, 48 (50.5\%) were male and 47 (49.5\%) were female. Mean age of presentation was 40 years. The right eye was affected in 48 $(50.5 \%)$ cases and the left eye in $43(45.3 \%)$ cases and bilateral in $4(4.2 \%)$ cases. The most common cause of facial palsy was Bell's palsy (70.5\%) [Table]. Some of the other causes were diseases of the parotid 5.3\%, congenital facial palsy $4.2 \%$, Hansen's $4.2 \%$, post excision of acoustic neuroma $4.2 \% ; 57.5 \%$ of patients had inferior punctate keratopathy on initial presentation, while $42.5 \%$ had clear cornea. 4 patients who had undergone neurosurgery for acoustic neuroma had impaired corneal sensation. One patient with Hansen's had inferior corneal pannus and one patient with Ramsay Hunt Syndrome was found to have corneal infiltrate in the affected eye of less than $2 \mathrm{~mm}$, which subsided with topical antibiotic therapy. Of the systemic associations diabetes alone was found in $11.25 \%$ of patients, hypertension alone in $6.25 \%$ and diabetes and hypertension in $8.75 \%$ of patients. One 30 -yearold male had been treated for pulmonary tuberculosis.

There were 19 patients who underwent surgery, out of which 8 patients in Group 1 (Description for groups has been given in materials and methods) who underwent gold weight implant in the upper eyelid. 3 patients in Group 2 underwent LTS only and one required an MSS. 2 patients in Group 3 underwent LTS, MSS and GWI. There were 2 patients in Group 4 who required a brow lift. 4 patients in Group 5, all of them who had undergone excision of acoustic neuroma, underwent lateral tarsorrhaphy only.

\begin{tabular}{|c|c|c|c|}
\hline Sl. No. & Causes & No. of Patients & $\mathbf{\%}$ \\
\hline 1 & Bell's palsy & 67 & $70.5 \%$ \\
\hline 2 & Congenital & 5 & $5.3 \%$ \\
\hline 3 & $\begin{array}{c}\text { Ramsay Hunt } \\
\text { syndrome }\end{array}$ & 2 & $2.1 \%$ \\
\hline 4 & Post-traumatic & 2 & $2.1 \%$ \\
\hline 5 & Parotid related & 5 & $5.3 \%$ \\
\hline 6 & Acoustic Neuroma & 4 & $4.2 \%$ \\
\hline 7 & Mastoidectomy & 2 & $2.1 \%$ \\
\hline 8 & Hansen's & 4 & $4.2 \%$ \\
\hline 9 & Miscellaneous & 4 & $4.2 \%$ \\
\hline \multicolumn{4}{|c|}{ Table 1 } \\
\hline
\end{tabular}

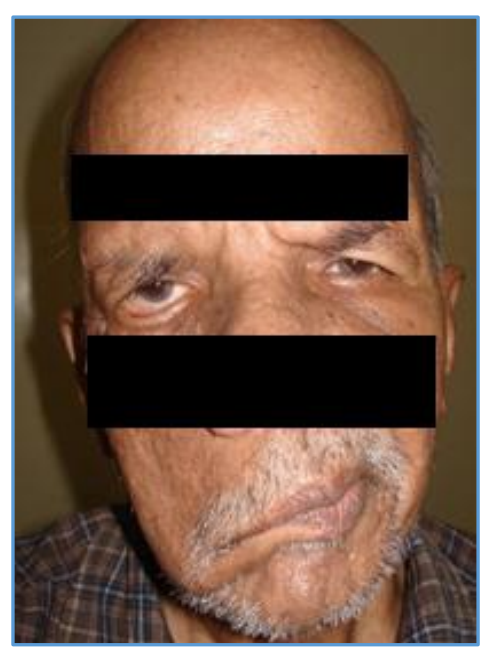

Figure 1. Showing Right LMN Facial Palsy with Brow Ptosis, Paralytic Ectropion, Facial Slant and Drooping of the Angle of Mouth 


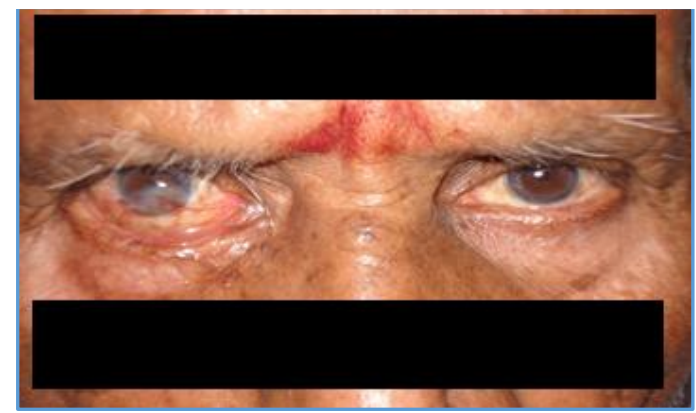

Figure 2. Showing an Elderly Patient with Long Standing Facial Nerve Palsy. There is Paralytic Ectropion, Conjunctival Congestion and Exposure Keratitis

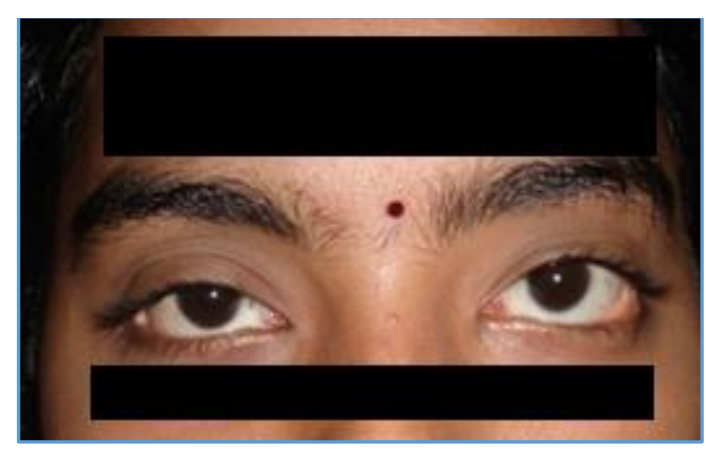

Figure 3a. Left Congenital Facial Nerve Palsy. There is Absence of Brow Ptosis and Paralytic Ectropion

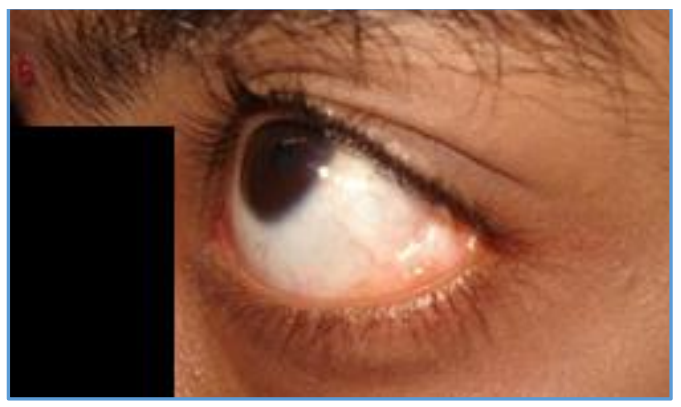

Figure 3b. Congenital Facial Nerve Palsy with associated Dermolipoma

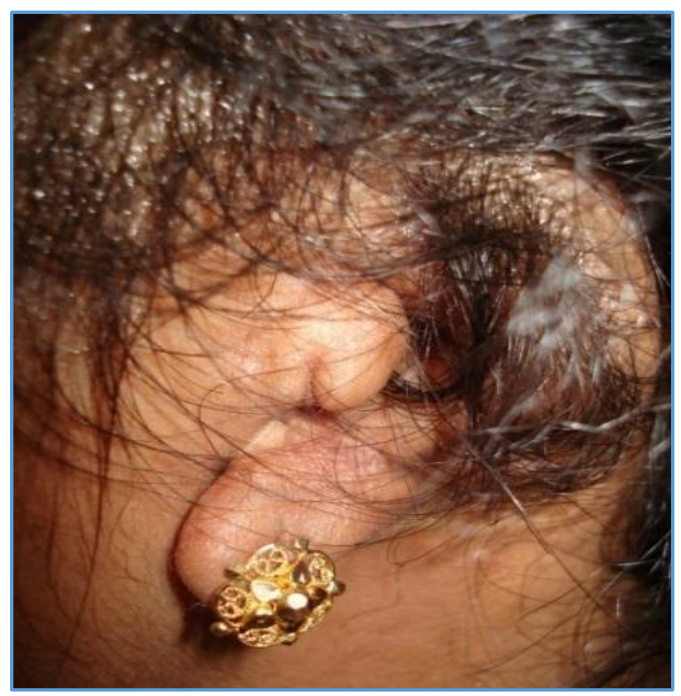

Figure 3c. Same patient with associated Microtia. External Ear Reconstruction has been Done

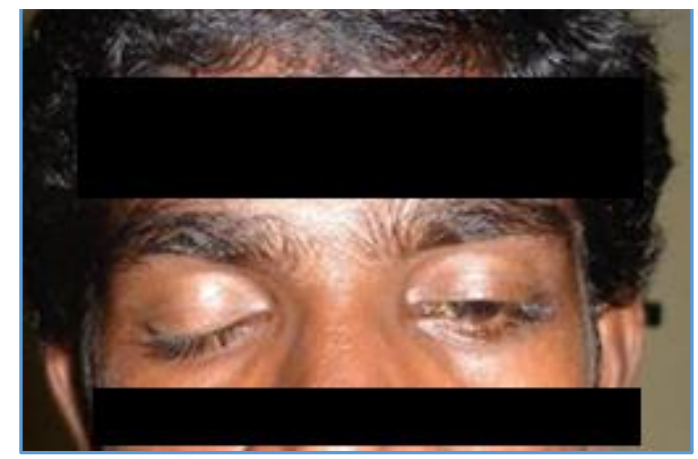

Figure 4a. A 30-year-old male with Lagophthalmos of the Left Eye

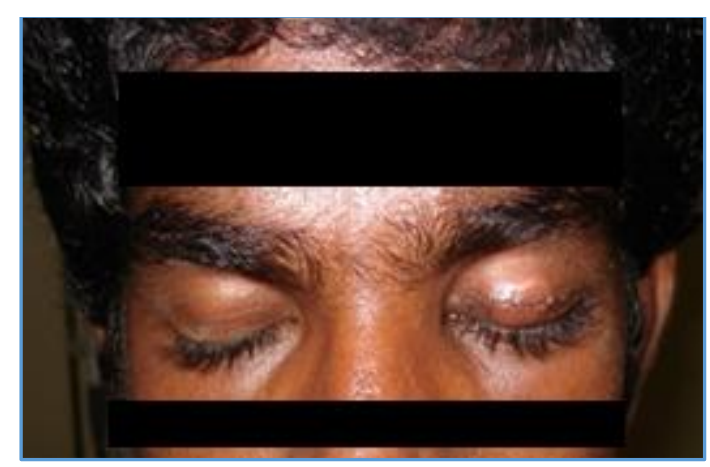

Figure 4b. Same patient Post Gold Weight Implant

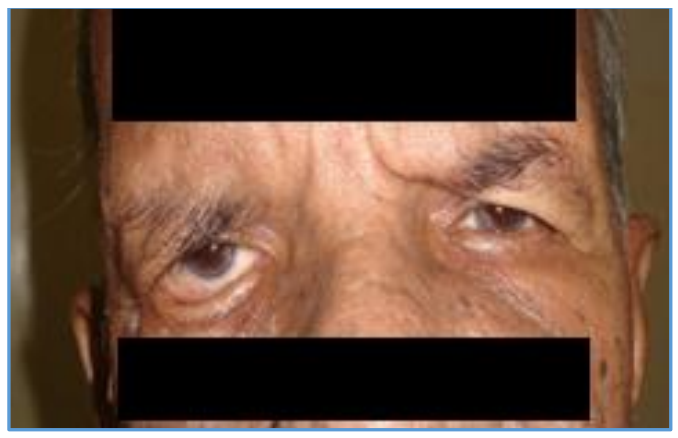

Figure 5a. An Elderly Male with Right Brow Ptosis, Lagophthalmos and Paralytic Ectropion

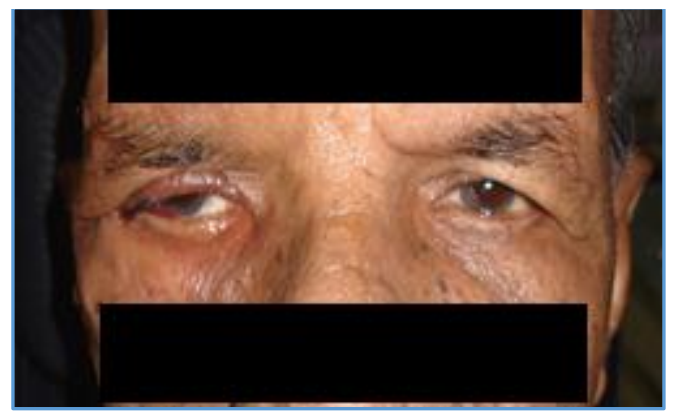

Figure 5b. Same patient following Gold Weight Implant, LTS and MSS

\section{DISCUSSION}

The various surgical techniques used in the management of facial palsy sequelae in this study- 


\section{Gold Weight Implantation}

After injecting local anaesthetic, pretarsal pocket is created by dissecting the skin and orbicularis off the tarsus inferiorly stopping 2 to $3 \mathrm{~mm}$ above the eyelashes and the gold weight implant is anchored to the tarsus with 6-0 prolene sutures. Then the wound is closed in layers.[1]

\section{Lateral Tarsal Strip}

Lateral tarsal strip is a procedure in which lower lid is shortened at the lateral canthus. First, a lateral canthotomy is performed. Then, a cantholysis is done by releasing the lower limb of lateral canthal tendon from the inferior orbital rim. Then a tarsal strip is formed, shortened after denuding the conjunctival epithelium and reattached to the inner aspect of lateral orbital rim. Redundant anterior lamella is trimmed followed by closure of canthotomy.[1]

\section{Medial Spindle Stitch}

After injecting local anaesthetic into the conjunctiva and skin on the medial one-third of the lid, a diamond shaped conjunctiva is excised and double armed 6-0 absorbable suture is passed through the lower lid retractors, then apex near the punctum, then apex inferiorly and out full thickness through the lid thereby inverting the lid.[1]

\section{Lateral Tarsorrhaphy}

Anterior and posterior lamellae of the eyelid is separated by Westcott scissors after incising the lid margins along the gray line for lateral one-third of upper and lower eyelids. Then the margin of posterior lamellae is de-epithelialised. Then, the upper and lower posterior lamellae are sutured together. Finally, the anterior lamellae are sewed together using absorbable sutures, placing the eyelashes in an everted position.[1]

\section{Transeyelid Browplasty}

The brow is anchored to the periosteum of the forehead internally using 4-0 Vicryl suture.[1]

\section{Clinical Anatomy and Background of Medical Management in Facial Nerve Palsy}

It is very important to know the course and anatomy of facial nerve to arrive at a diagnosis as to where the lesion is located. The facial nerve not only supplies facial muscles, but also involves in various functions through different branches such as greater superficial petrosal nerve (reflex tearing), nerve to stapedius (Hearing), chorda tympani (Taste on the anterior two-thirds of the tongue), branches to sublingual and submandibular salivary glands (Salivation). ${ }^{[5,6]}$ The diagnosis of acquired involvement at various levels of facial nerve is facilitated by the knowledge of the relationship of facial nerve to surrounding structures within the brainstem, cerebellopontine angle and the facial canal and by the fact that during its course the nerve gives off various branches that subserve specific functions. Thus, patients should undergo a careful clinical examination during which all of the functions served by the nerve are tested. In addition various electrodiagnostic tests, particularly those of nerve conduction, are of value both in diagnosis and prognosis of facial nerve dysfunction. Electrodiagnostic tests such as nerve excitability test, trigeminal blink reflex done within 14 days of onset can be useful in prognostic information.[7] Prognosis for recovery of Bell's palsy depends on a number of variables such as rate of recovery, age of the patient, time of commencement of steroids and degree of weakness at the time of presentation (complete or partial).[7] Some evolving treatment for facial nerve palsies include methylcobalamin, hyperbaric oxygen, transcutaneous electrical stimulation, neurotrophic growth factors, neuroprotective agents- for example nimodipine, glial cell derived neurotrophic factor, vaccination against herpes zoster virus and herpes simplex virus types 1 and 2.[8]

\section{CONCLUSION}

This study was a hospital-based, single-centre, retrospective review of LMN facial palsy. Bell's palsy was found to be the most common cause of LMN facial palsy (70.5\%). This is similar to the incidence quoted by Murthy J et al.[10] The mean age of Bell's palsy was 40 years, which is similar to that of Murthy J[10] and Tiemstra JD et al.[11] Congenital facial palsy was found in 4 patients, all of whom had associated microtia (Fig. 3a-c). This is in contrast to other studies of facial nerve palsy, where congenital causes were much lower or not seen at all. This could be attributed to the fact that this was a record-based study of patients who attended a multidisciplinary hospital.

The association of diabetes in all cases of facial nerve palsy was $11.25 \%$ and that in Bell's palsy was $16.9 \%$. This is higher than what was found by Yanagihara $\mathrm{N}$ et al who studied 625 patients with Bell's palsy.[12] Bell's palsy resolved between one to three months in most patients. Punctate epitheliopathy of inferior cornea reduced in a week's time in 34 patients and resolved completely in two weeks' time in 8 patients after continued application of tear substitutes.

Of the 8 patients who underwent gold weight implant, lagophthalmos was reduced to grade 2 in 6 patients. The implant was removed in one patient with congenital facial nerve palsy due to the increased prominence of the implant in the upper eyelid following surgery.

Peripheral facial palsy formerly thought to be idiopathic is now thought to be of viral aetiology, mostly Herpes Simplex virus.[13] Bell's palsy of less than a week in duration responds well to systemic antiviral, steroids and tear substitutes. Studies have been made to detect the efficacy of single dose IV steroids instead of oral steroids and showed equal efficacy.[14] Hyaluronic acid gel, gold weight implant have all been described as lid loading procedures for lagophthalmos.[15,16] Botulinum toxin chemodenervation has evolved greatly over the past 30 years since its introduction in the $1970 \mathrm{~s}$ for the management of strabismus. Chemotarsorrhaphy is effectively a good procedure for achieving temporary ptosis for corneal protection. Doses ranging from $2.5 \mathrm{U}$ upto $20 \mathrm{U}$ of Botox have been used. It can also be used to treat aberrant regeneration of facial nerve.[17] Surgical decompression of facial nerve still remains controversial in treatment of facial nerve palsy and should be used only in refractory cases.[18]

We recommend gold weight implant as it is cost effective, provides good eyelid closure and can easily be removed if required. For facial palsy lasting for more than six months, an appropriate surgical procedure is planned based on the patient's age, the type of sequelae and the requirements of patients. Lateral tarsal strip produces good apposition of the lower lid to globe. 
A combination of gold weight implant with corrective procedures for paralytic ectropion and brow ptosis greatly improves cosmesis, upper eyelid closure, reduces lagophthalmos and exposure keratitis and decreases the frequency of ocular lubricants. Where there is impaired corneal sensation, lateral tarsorrhaphy is still the procedure of choice.

\section{REFERENCES}

[1] Nerad JA. Oculoplastic surgery. The requisites in Ophthalmology. Abnormal movements of face. Mosby/Elsevier Health Sciences 2001: p. 201-13.

[2] Alsuhaibani AH. Facial nerve palsy: providing eye comfort and cosmesis. Middle East Afr J Ophthalmol 2010;17(2):142-7.

[3] Bergeron CM, Moe KS. The evaluation and treatment of upper eyelid paralysis. Facial Plast Surg 2008;24(2):220-30.

[4] Razfar A, Afifi AM, Manders EK, et al. Ocular outcomes after gold weight placement and facial nerve resection. Otolaryngol Head Neck Surg 2009;140(1):82-5.

[5] Bron AJ, Tripathi RC, Tripathi BJ. Wolff's anatomy of the eye and orbit. $8^{\text {th }}$ edn. London: Chapman \& Hall Medical 1997: p. 46-50, 205-9.

[6] Standring S. Gray's Anatomy. The anatomical basis of clinical practice. $40^{\text {th }}$ edn. Churchill Livingstone/Elsevier 2008: p. 481-9.

[7] Stew B, Williams H. Modern management of facial palsy: a review of current literature. The British Journal of General Practice 2013;63(607):109-10.

[8] Holland NJ, Weiner GM. Recent developments in Bell's palsy. BMJ: British Medical Journal 2004;329(7465):553-7.

[9] Miller NR. Walsh and Hoyt's clinical neuroophthalmology. $4^{\text {th }}$ edn. Vol. 2. Williams \& Wilkins 1991: p. 1560-4.
[10] Murthy JMK, Saxena AB. Bell's palsy: treatment guidelines. Ann Indian Acad Neurol 2011;14(Suppl 1):S70-S2.

[11] Tiemstra JD, Khatkhate N. Bell's palsy: diagnosis and management. Am Fam Physician 2007;76(7):9971002.

[12] Yanagihara N, Hyodo M. Association of Diabetes mellitus and hypertension with Bell's palsy and Ramsay Hunt syndrome. Ann Otol Rhinol Laryngol Suppl 1988;137:5-7.

[13] Murakami S, Mizobuchi M, Nakashiro Y, et al. Bell palsy and herpes simplex virus: identification of viral DNA in endoneural fluid and muscle. Ann Intern Med 1996;124(1 Pt 1):27-30.

[14] Giri P, Garg RK, Singh MK, et al. Single dose intravenous methyl prednisolone versus oral prednisolone in Bell's palsy: a randomized controlled trial. Indian Journal of Pharmacology 2015;47(2): 143-7.

[15] Finsterer J. Management of peripheral facial nerve palsy. Eur Arch Otorhinolaryngol 2008;265(7):743-52.

[16] Mancini $R$, Taban M, Lowinger A, et al. Use of hyaluronic acid gel in the management of paralytic lagophthalmos: the hyaluronic acid gel "gold weight". Ophthal Plast Reconstr Surg 2009;25(1):23-6.

[17] Naik MN, Soparker CNS, Murphy R, et al. Botulinum toxin in ophthalmic plastic surgery. Indian J Ophthalmol 2005;53(4):279-88.

[18] Zandian A, Osiro S, Hudson R, et al. The neurologist's dilemma: a comprehensive clinical review of Bell's palsy, with emphasis on current management trends. Medical Science Monitor 2014;20:83-90. 